\title{
The Simulation of Flood Hydrograph in Natural and Urban Basins
}

\author{
Seyyed Ahmadreza Torabi', Hossein Sedghi' ${ }^{1}$, Jahangir Porhemmat ${ }^{2 *}$, Hossein Babazadeh ${ }^{1}$ \\ ${ }^{1}$ Department of Water Science and Engineering, Science and Research Branch, Islamic Azad University, Tehran, Iran \\ ${ }^{2}$ Soil Conservation and Watershed Management Research Institute (SCWMRI), Tehran, Iran \\ Email: *Porhemmat@scwmri.ac.ir
}

How to cite this paper: Torabi, S.A., Sedghi, H., Porhemmat, J. and Babazadeh, H. (2018) The Simulation of Flood Hydrograph in Natural and Urban Basins. Open Journal of Geology, 8, 641-646. https://doi.org/10.4236/ojg.2018.87037

Received: July 31, 2017

Accepted: July 7, 2018

Published: July 10, 2018

Copyright (c) 2018 by authors and Scientific Research Publishing Inc. This work is licensed under the Creative Commons Attribution International License (CC BY 4.0).

http://creativecommons.org/licenses/by/4.0/

\begin{abstract}
The exact estimation of the flood is one of the main concerns for designers of the water bodies. The significance of this issue in the catchment areas overlooking the cities is more and more visible. In this study, HEC-HMS model is used to simulate the catchment area of the Khoshk River in the Shiraz city. The simulation results and its comparison with the observations based on Nash-Sutcliffe coefficient confirm the validity of the model. The input data of the model includes Rainfall, Measured Discharge, Flood Peak Time, Curve Number (CN), and so on. These results indicate that although the shape of the simulated hydrograph is not exactly the same as the observed hydrograph, it has estimated the peak of flood discharge well with an error rate of two to five percent.
\end{abstract}

\section{Keywords}

Hydrologic Model, Discharge Peak, Flood, HEC-HMS

\section{Introduction}

Population growth, urban development and industrialization of the communities have adversely affected the hydrology of the catchment area, which exacerbates the floods, increases pollution in the riffle, decreases the base flow and reduces the nutrition of groundwater. Increasing the impenetrable levels of these areas affected by this trend, reduced their permeable level, which plays a major role in absorbing rainfall, and subsequently adds to the total volume of runoff [1] [2] [3]. The result of these changes will shorten the focus time and increase the intensity of flood drainage in the area. [2], using the LISFLOOD model, investigated the role of land use change on peak flood discharge in the two Oder and Meuse areas. [4] [5] [6], by combining the HEC-HMS and HEC-RAS mod- 
els in GIS, analyzed different flood control options and selected the best option. Also, [7] presented a regional flood model with a combination of these models in the San Antonio area and noted the model's efficiency in predicting flood events. Historical reports and documents show that the watersheds of southern Iran, especially Shiraz, have a high potential for flood [8] [9] [10]. Due to the lack and adequacy of the statistics of flood, especially in urban basins, this study attempted to compare the current method of estimating flood in these basins with actual statistics. To do this, we attempt to simulate the flood hydrograph in the natural and urban basin of the dry river of Shiraz using the HEC-HMS software.

\section{Location of Study}

Part of the catchment area of the Shiraz Khoshk River with an area of 900.3 square kilometers is located between the geographical lengths of eastern $52^{\circ} 12^{\prime} 30^{\prime \prime}$ to $52^{\circ} 41^{\prime} 30^{\prime \prime}$ and north geographical latitudes of $29^{\circ} 34^{\prime} 37^{\prime \prime}$ to $29^{\circ} 58^{\prime} 07^{\prime \prime}$. This area is bounded to the northern plains of Zareghan and Beyza and from south to Shiraz city, from the east to the Maharloulake and from the west to the Shool col. The only river in this basin is the seasonal river, which has no water flow in the dry months. The nourishing sub-basins of the Khoshkriver are: Nahr Azam, Ali Abad, Chenar Sokhteh and Chenar Rahdar, which totally are four sub-basins. Their specifications are presented in Table 1.

\section{Statistics and Required Data}

The meteorological stations network in the study area includes six rational stations, one synoptic station and five hydrometric stations. The length of the station's statistical period varies from seven to fifty five years, which was eliminated for better use of this short-term station score. Finally, a 20-year common period was used from the year 1985 to 2005, and incomplete stations statistics with correlation method was reconstructed. Here, we study the Khoshk River catchment area, which is the data required for the model is the amount of CN (Curve Number) that is used by the soil map of the province of Fars and the basin boundary that has been digitized in the GIS software. Subsequently, the map of the hydrological groups in terms of depth and the soil texture of the basin are prepared.

\section{HEC-HMS Model}

To run this model, some parameters are needed, such as: initial losses, the conversion of excess precipitation to surface flow, determination of base flow, calibration and validity of the model, which will be explained below the calculation method of each one.

\section{Basin Losses}

Some of these factors include interception, evapotranspiration and reservoir 
Table 1. Parameter specifications.

\begin{tabular}{ccccccc}
\hline Row & Parameter & Unit & Nahr Azam & Chenar Sokhteh & Ali Abad & Chenar Rahdar \\
\hline 1 & Area & Square kilometer & 193.161 & 70.999 & 78.101 & 396.081 \\
2 & Environment & Kilometer & 65.143 & 40.666 & 52.078 & 101.036 \\
3 & Graviolus coefficient & - & 1.312 & 1.351 & 1.650 & 1.421 \\
4 & Rectangular equivalent length & Kilometer & 24.775 & 15.855 & 22.580 & 40.813 \\
5 & Rectangle width equivalent & Kilometer & 7.797 & 4.478 & 3.459 & 9.705 \\
6 & Circular ratio & - & 0.581 & 0.548 & 0.367 & 0.495 \\
7 & Coefficient of shape & - & 0.315 & 0.282 & 0.153 & 0.238 \\
8 & Shape index & - & 3.178 & 3.541 & 6.528 & 4.206 \\
9 & Circle diameter of same surface of the circle & Kilometer & 15.682 & 9.508 & 9.972 & 22.457 \\
10 & Medium slope of the field [basin] & Percent & 23.890 & 22.680 & 31.750 & 17.570 \\
11 & Main drainage length & Kilometer & 25.450 & 6.972 & 18.950 & 43.053 \\
12 & Net slope of main flow & Percent & 2.458 & 4.328 & 1.832 & 1.182 \\
13 & Gross slope of main flow & Percent & 3.234 & 6.311 & 1.962 & 2.065 \\
14 & Cerpitch focus time & Hour (time) & 3.341 & 0.992 & 2.981 & 6.640 \\
15 & Brans Williams focus time & Hour (time) & 4.824 & 1.476 & 3.715 & 8.077
\end{tabular}

water in the holes. There are 7 different methods for calculating these factors. In this research, the SCS method is used.

$$
\begin{gathered}
P e=(P-I a)^{2} /(P-I+S) \\
I a=0.2 S \\
S=(25400-254 C N) / C N
\end{gathered}
$$

Pe: Height of Effective Precipitation (Run off) (mm).

$P$. Height of Precipitation ( $\mathrm{mm}$ ).

$S$ : Maximum Potential Storage of Basin ( $\mathrm{mm})$.

$C N$ : Curve Number.

Ia: Initial Loss $(\mathrm{mm})$.

\section{Transfer Model}

The SCS hydrograph method is used to convert excess precipitation to surface flow.

$$
\begin{gathered}
U p=2.08 \mathrm{~A} / \mathrm{Tp} \\
T p=\Delta t / 2+t_{\text {lag }} \\
t_{\text {lag }}=L^{0.5}(S+1)^{0.7} / 1900 \mathrm{~W} \\
S=1000 / C N-10
\end{gathered}
$$

\section{Calibration}

In this part, the parameters of the model are calibrated with the group of data. Then, model validation is performed through the run of the model with 


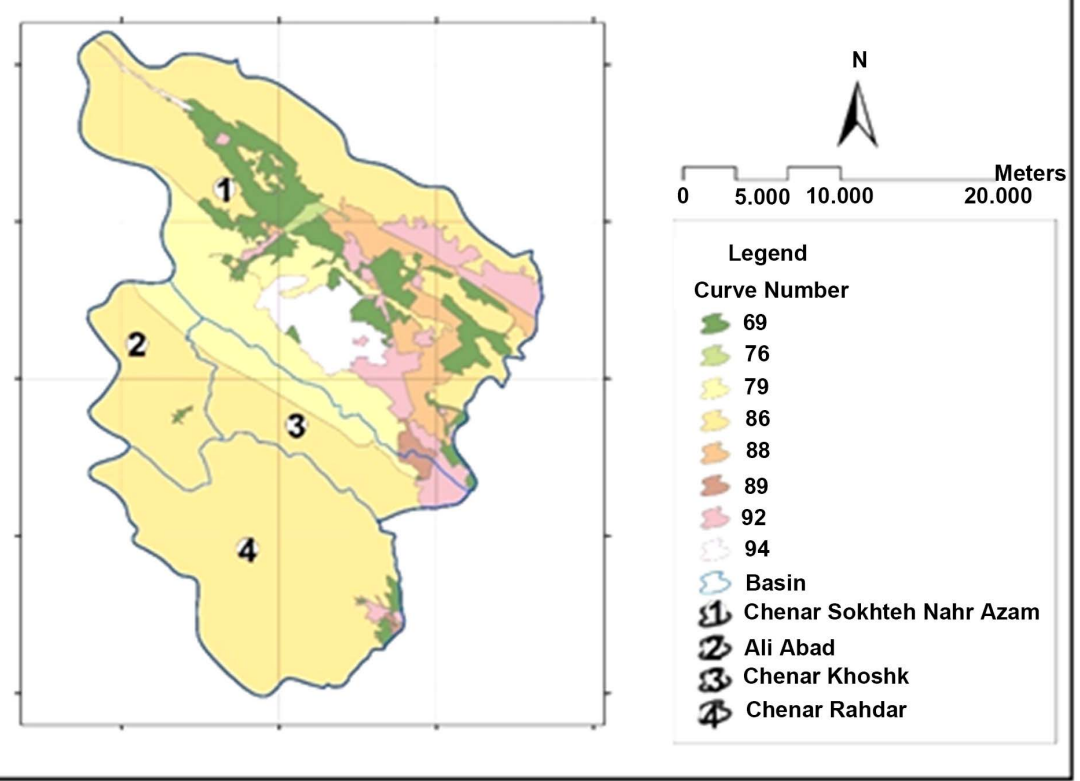

Figure 1. CN map.

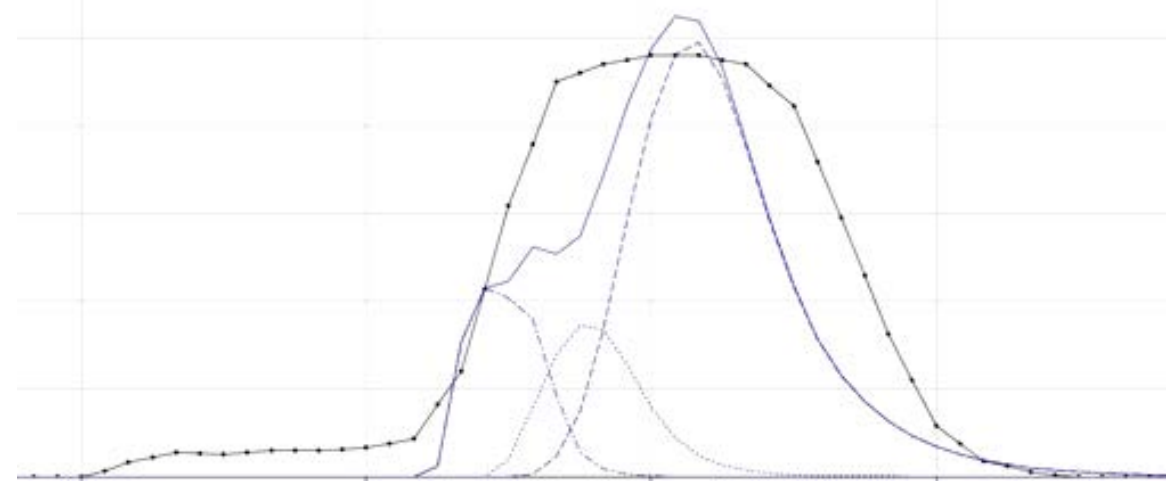

Figure 2. The calibration results.

Table 2. CN Values and primary losses.

\begin{tabular}{ccc}
\hline The name of the sub-basin & CN & Primary losses \\
\hline Ali Abad & 85.19 & 16.76 \\
Chenar Sokhteh khoshk & 84.39 & 17.50 \\
Chenar Rahdar & 85.82 & 17.50 \\
Chenar Sokhteh Nahr Azam & 83.33 & 18.49
\end{tabular}

optimized parameters for the second group of data and finally, the simulated hydrograph is compared with the observed hydrograph. Also, in the validation phase, using the Nash-Sutcliff and variance coefficient were evaluated. It should be said when the coefficient of variance is lower the performance of the model will be higher. In the criterion of the Nash-Sutcliff, one indicates the complete matching of the simulation and observation hydrograph. 
Table 3. Hydrologic element results.

\begin{tabular}{cccc}
\hline Hydrologic Element & $\begin{array}{c}\text { Simulated Peak Discharge } \\
\mathrm{m}^{3} / \mathrm{s}\end{array}$ & $\begin{array}{c}\text { Observed Peak Discharge } \\
\mathrm{m}^{3} / \mathrm{s}\end{array}$ \\
\hline 1 & Chenar Sokhteh Nahr Azam & 49.2 & 48 \\
2 & Chenar Sokhteh khoshk & 18 & 17.33 \\
3 & Ali Abad & 28.3 & 27.1 \\
& Out 1+2 & 39.5 & 37.95 \\
& Out 1 + 2+3 & 51.6 & 50.41 \\
4 & Chenar Rahdar & 41.6 & 40.35 \\
\hline
\end{tabular}

Qoi, Qsi observed and simulated values Qo mean of observed discharge.

\section{Research Methodology}

In order to simulate the flood hydrograph, HEG-HMS 4.2 model we used. Firstly, using ARCGIS, topography maps, vegetation, land use and soil hydrological groups were provided and integrating land use maps and soil hydrologic groups the $\mathrm{CN}$ map was prepared and its mean values were determined for sub-basins. In order to determine the values of Intensity-Duration-Frequency using the suggested method Qahraman-Abkhezr, the amount and intensity of rainfall were calculated. Figure 1 shows the prepared CN map. The values of the $\mathrm{CN}$ and the calculated primary losses for the studied sub-basins are shown in Table 2 .

Then, by inserting the calculation (primary losses, CN, lag time, area of basin, rainfall values, etc.), in the HEC-HMS, the model was implemented (Figure 2). The Soil Conservation Service (SCS) method was used for the flow and water losses and the results are presented in the Table 3.

Using the Nash coefficient and the sum of the squared error, the model was calibrated. The flood of November 1986 and December 2001 confirmed the model's accuracy. The estimation of the Nash criteria in the sub-basins of Chenar Sokhteh Nahr Azam, Ali Abad, Chenar Sokhteh Khoshk, and Chenar Rahdaris $0.74,0.83,0.71$ and 0.85 , respectively. The calibration results of the model as an example in the event of the year 2001 is presented in Figure 2.

\section{Discussion and Conclusion}

Investigating the results of the HEC-HMS model in the catchment basin of the Shiraz Khoshk River indicates that although the volume of the flood and the shape of the simulated hydrograph are not consistent with the observed hydrograph, nevertheless, it has estimated the peak flood discharge well with an error rate of two to five percent.

\section{References}

[1] Ashoori, M., Bahadori Khosroshahi, F. and Arhami, M. (2007) Investigating the Effects of Urban Development on Rising Runoff, A Case Study of Darabad-North Ba- 
sin in Tehran. Sixth Iranian Hydraulic Conference, Shahrekord, 254-261 September 2007, 54-68.

[2] Baharloo, S.M.A. and Abdollahi, M. (2008) Hydrological Response Forecast of Maroon Basin versus Urban Development by HEC-HMS Software. Undergraduate Thesis, Islamic Azad University, Marvdasht.

[3] Jokar, J. (2002) Investigation of Flooding of Shapur River Sub-Basins Using Flood Flows Simulation. Master Thesis, Faculty of Natural Resources and Marine Sciences, Tarbiat Modarres University, Tehran, 126.

[4] Hajigolizadeh, M. (2004) Investigating the Role of Human Intervention on Flood Behavior in a Part of the Kan River. Master Thesis, Faculty of Natural Resources and Marine Sciences, Tarbiat Modarres University, Tehran, 128.

[5] Khosroshahi, M. (2001) Determining the Role of Sub-Basins in the Flood Intensity of the Area (Case Study of Damavand Watershed). Doctoral Dissertation, Faculty of Humanities, Tarbiat Modarres University, Tehran, 177.

[6] Taheri Behbahani, M.T. and Bigzadeh, M. (1996) Urban Flood. Publication Center for Urban and Architecture Studies and Research, Tehran, Iran.

[7] Benavides, J.A., Pietruszewski, B., Kirsch, B. and Bedient, P. (2003) Analyzing Flood Control Alternatives for the Clear Creek Watershed in A Geographic Information System Framework. Proceedings of ASCE EWRI Conference on Bridging the Gap: Meeting the World's Water and Environmental Resources Challenges, CD-ROM.

[8] De Hoo, A., Odijk, M., Koster, E. and Lucieer, A. (2001) Assessing The Effects of Land Use Changes on Floods in The Meuse and Oder Catchments. Physics and Chemistry of the Earth, Parts B, 26, 593-599. https://doi.org/10.1016/S1464-1909(01)00054-5

[9] Knebl, M.R., Yang, Z.L., Hutchison, K. and Maidment, D.R. (2005) Regional Scale Flood Modeling using NEXRAD, Rainfall, GIS, and HEC-HMS $\backslash$ RAS: A Case Study for the San Antonio River Basin Summer 2002 Storm Event. Journal of Environmental Management, 75, 325-336. https://doi.org/10.1016/j.jenvman.2004.11.024

[10] Ghahraman, B. and Abkhezr, H. (2004) Improvement in Intensity-Duration-Frequency Relationships of Rainfall in Iran. JWSS, 8, 1-14. 